\title{
DEVELOPMENT AND DETERMINATION OF VOLTAGE-FAULT- LOCATION AND LINE-FAULT-LOCATION (LENGTH OF LINE) ON LONG TRANSMISSION-LINE (200 MILE = 320 KM) (IFLM)
}

\author{
S.L. Braide ${ }^{1}$ \\ ${ }^{I}$ Department of Electrical/Computer Engineering, Rivers State University of Science and Technology, Port Harcourt, \\ Nigeria
}

\begin{abstract}
Fault location and fault-voltage problems have been presented as a major challenge in electrical power system analysis, most of these methods uses voltage and currents measurements at either one ends or both ends of a transmission line. This work presents a faultlocation/fault-voltage problems. An improved fault location model (IFLM) are developed to search for fault location in a long transformation line say (200 mile), thereby determining a set of values for a set of unknown system state variables, based on certain criterion making use of the measurements mode from the system under consideration.
\end{abstract}

Keywords: Fault Location, fault-voltage-location-long transmission line, impedance matrix, Admittance line-faultlocation and voltage buses.

****.

\section{INTRODUCTION}

Fault location in a long transmission line $(200$ mile $=320 \mathrm{~km})$ using an improved fault-location model (IFLM) are described and presented. Many contributions have been made by different references based on: the use of voltage and currents phasor one terminal which is based on reactive power, use of voltage and currents phasor at both ends, use of three-phase analysis and which uses a least - square - estimate to obtain fault point distance, the method is to convert time domain and then use critical neutral network to estimate fault location. This work formulate and presents a model based on impedance matrix and estimation, based on impedance equation, that are applied on a transmission line to determine fault voltage/fault location. [1]

\section{ANALYSIS AND MODEL: THE PROPOSED}

\section{MODEL (IFLM)}

Consider a transmission line as shown in fig. 1.0 for analysis. The three phase - source impedance matrices are $Z_{\text {slabc }}(\Omega)$ and $Z_{\text {S2abc }}(\Omega)$. These are assumed to be known and equal the Thevenin equivalent system models of bus 1 and 2 respectively. " $\mathrm{L}$ " is the length of the long-transmission line $(200$ mile $=320 \mathrm{~km})$. The transmission line has three-phase impedance $Z_{\mathrm{abc}} \Omega /$ mile (formed by self and mutual impedance among phases). [2,3]
That can be presented in the form: 3-phase [a $\mathrm{b} c$ ]

$$
\begin{aligned}
& Z a b c=\left[\begin{array}{lll}
Z a a & Z a b & Z a c \\
Z b a & Z b b & Z b c \\
Z c a & Z c b & Z c c
\end{array}\right] \\
& \text { Or }- \\
& Z_{123}=\left[\begin{array}{lll}
Z_{11} & Z_{12} & Z_{13} \\
Z_{21} & Z_{22} & Z_{23} \\
Z_{31} & Z_{32} & Z_{33}
\end{array}\right]
\end{aligned}
$$

- $\quad$ For a three - phase analysis this line would yield a bus impedance/admittance. The bus admittance matrix will take the form:

$$
Z_{\text {Bus }}=\left[\begin{array}{ll}
Z_{11} & Z_{12} \\
Z_{21} & Z_{22}
\end{array}\right] \text { - }
$$

Or

$Y_{\text {Bus }}=\left[\begin{array}{ll}Y_{11} & Y_{12} \\ Y_{21} & Y_{22}\end{array}\right] \quad--\quad-$ 
- $\quad$ From equ. (2) the element is a matrix of Dimension $3 \mathrm{x}$ 3 ; as shown in fig. 2 , the fault point considered as the third bus. The third bus is consider to be the faulted bus. Then the change in the bus voltages on all the three buses due to the fault can be obtained by the following equation: [4]

$$
\left[\begin{array}{l}
\Delta V_{1} \\
\Delta V_{2} \\
\Delta V_{3}
\end{array}\right]=Z_{\text {bus }} \text { fault }\left[\begin{array}{c}
{[0]} \\
{[0]} \\
I_{F a b c}
\end{array}\right]-
$$

- Similarly, a case when the reactance are not given, therefore it is convenience to obtain $\mathrm{Z}_{1 \mathrm{Bus}}$ directly rather than inventing $\mathrm{Y}_{1 \text { Bus. }}$.

- Also if $\mathrm{Y}_{0, \mathrm{Bus}}$ is singular and then $\mathrm{Z}_{\mathrm{o}, \mathrm{Bus}}$ cannot be obtained from it.

- Hence, in such conditions above, we can apply a simple technique of unit current - injections approach. [5,6]

- $\quad$ That is for the 2-Bus in fig. 1.0 above, we can write the matrix equation relating voltage and currents, as:

$$
\left[\begin{array}{l}
V_{1} \\
V_{2}
\end{array}\right]=\left[\begin{array}{ll}
Z_{11} & Z_{12} \\
Z_{21} & Z_{22}
\end{array}\right]\left[\begin{array}{l}
I_{1} \\
I_{2}
\end{array}\right] \text { - }
$$

- Now injecting unit currents at bus 1 (that is $I_{1},=1$, and $\mathrm{I}_{2}=0$ )

Then we have:

$$
\begin{array}{llll} 
& \mathrm{Z}_{\mathrm{II}} & = & \mathrm{V}_{1} \\
\mathrm{Z}_{21} & = & \mathrm{V}_{2} &
\end{array}
$$

- $\quad$ Similarly, by injecting a units currents at bus 2 (that is $\mathrm{I}_{2}=1, \mathrm{I}_{1}=0$ ), then we have:

$$
\begin{array}{llll} 
& \mathrm{Z}_{12} & = & \mathrm{V}_{1} \\
\mathrm{Z}_{22} & = & \mathrm{V}_{2} & -
\end{array}
$$

This, $Z_{\text {bus }}$ could be obtained directly by this idea:

$$
Z_{\text {Bus }}=\left[\begin{array}{ll}
Z_{11} & Z_{12} \\
Z_{21} & Z_{22}
\end{array}\right]=\left[\begin{array}{ll}
V_{1} & V_{1} \\
V_{2} & V_{2}
\end{array}\right] \text { - }
$$

Now, interpreting the parameters of equation (4) we have: [O]: null matrix of dimension is $(3 \times 1)$

$\mathrm{I}_{\mathrm{Fabc}}$ : Three phase fault current at the faulted bus 3; dimension of $I_{\text {Fabc }}$ is $(3 \times 1)$.
$\Delta$ Vi: Change in the three phase voltages of bus 1 due to the fault at bus three.

$\Delta \mathrm{Vi}$, dimensions $(3 \times 1)$.

$Z_{\text {Busfault: }}$ Three phase bus-impedance matrix with the fault considered at bus three dimensions is $(9 \times 9)$ rewriting equation (4) we have:

$$
=Z_{\text {bus }} \text { fault }\left[\begin{array}{c}
{[0]} \\
{[0]} \\
I_{F a b c}
\end{array}\right]=\left[\begin{array}{c}
\Delta V_{1} \\
\Delta V_{2} \\
\Delta V_{3}
\end{array}\right]
$$

Or

$$
\left[\begin{array}{c}
{[0]} \\
{[0]} \\
I_{F a b c}
\end{array}\right]=Z_{\text {bus }} \text { fault }^{-1}\left[\begin{array}{c}
\Delta V_{1} \\
\Delta V_{2} \\
\Delta V_{3}
\end{array}\right]
$$

Similarly we have:

$$
\left[\begin{array}{c}
{[0]} \\
{[0]} \\
I_{F a b c}
\end{array}\right]=Y_{\text {bus }} \text { fault }\left[\begin{array}{c}
\Delta V_{1} \\
\Delta V_{2} \\
\Delta V_{3}
\end{array}\right] \text { - }
$$

- In equation (4) $\mathrm{Y}_{\text {Busfault }}$ is the three-phase bus admittance matrix of dimension ( $9 \times 9$ ) which is equal to the inverse of $Z_{\text {Busfault }}$

- $\quad$ Each elements of $Y_{\text {Bus fault }}$ is a matrix of dimension (3x $3)$.

- Bus admittance matrices are related to the physical configuration of the corresponding power system.

- Elements of the Bus admittance matrix $Y_{\text {Bus }}$ (before fault) are known to us.

- $\quad$ Now using the correction of the system in fig.2 due to fault condition; the elements of $Y_{B u s}$ fault can be related to the elements of $Y_{\text {Bus }}$ as given as:

$$
Y_{\text {Busfault }}=\left[\begin{array}{lll}
Y_{11}^{\prime} & Y_{12}^{\prime}, & Y_{13}^{\prime} \\
Y_{21}^{\prime} & Y_{22}^{\prime} & Y_{23}^{\prime} \\
Y_{31}^{\prime} & Y_{32}^{\prime} & Y_{33}^{\prime}
\end{array}\right] \quad-
$$

Where:

$$
Y_{11}^{\prime}=Y_{11}-\frac{Y_{a b c}}{L}+\frac{Y_{a b c}}{L_{1}}-
$$




$$
\begin{gathered}
Y_{12}^{\prime}=\mathrm{Y}_{21}=[0]_{3 \times 3} \\
Y_{13}^{\prime}=Y_{31}=\frac{Y_{a b c}}{L_{1}} \\
Y_{22}^{\prime}=Y_{22}-\frac{Y_{a b c}}{L}+\frac{Y_{a b c}}{L_{2}} \\
Y_{23}^{\prime}=Y_{32}=-\frac{Y_{a b c}}{L_{2}} \\
Y_{33}^{\prime}=\frac{Y_{a b c}}{L_{1}}+\frac{Y_{a b c}}{L_{2}}+(Z a b c)^{-1}
\end{gathered}
$$

Where:

$\mathrm{L}_{1}$ and $\mathrm{L}_{2}$ : Are the distances of the fault point from bus 1 and 2 respectively, is shown in fig 2 .

$\mathrm{L}:$ is the total length of the transmission line $(200$ mile $=320$ $\mathrm{km})$

$\mathrm{Zf}_{\mathrm{abc}}$ is the three - phase fault impedance matrix.

$\mathrm{Y}_{\mathrm{abc}}$ : is the inverse of the three phase line impedance matrix per unit length gives as:

$$
Y_{a b c}=\frac{1}{\left(Z_{a b c}\right)}=(Z a b c)^{-1}
$$

From equations $(9,10,11,12, \ldots . .16)$ the following equation can be formulated, but we can recalled that;

$$
\left[\begin{array}{c}
{[0]} \\
{[0]} \\
I_{\text {Fabc }}
\end{array}\right]_{3 \times 3}=Y_{\text {bus }} \text { fault }\left[\begin{array}{c}
\Delta V_{1} \\
\Delta V_{2} \\
\Delta V_{3}
\end{array}\right]
$$

Then,

$$
[O]_{3 \times 3}=Y_{\text {Bus }}\left[\begin{array}{c}
\Delta V_{1} \\
\Delta V_{2} \\
\Delta V_{3}
\end{array}\right]
$$

Or

$$
[O]_{3 \times 3}=\left[\begin{array}{ccc}
O & O & O \\
O & O & O \\
O & O & O
\end{array}\right]
$$

$$
\left[Y_{\text {Bus fault }}\right]=\left[\begin{array}{lll}
Y_{11}^{\prime} & Y_{12}^{\prime} & Y_{13}^{\prime} \\
Y_{21}^{\prime} & Y_{22}^{\prime} & Y_{23}^{\prime} \\
Y_{31}^{\prime} & Y_{32}^{\prime} & Y_{33}^{\prime}
\end{array}\right]
$$

$$
\left[\begin{array}{l}
\Delta V_{1} \\
\Delta V_{2} \\
\Delta V_{3}
\end{array}\right]=\text { change at Bus } 1,2,3
$$

Where: $Y_{11}^{\prime}=Y_{11}-\frac{Y_{a b c}}{L}+\frac{Y_{a b c}}{L_{1}}$

$Y_{12}^{\prime}=$

$Y_{13}^{\prime}=$

$Y_{22}^{\prime}=$

$Y_{23}^{\prime}=$

$Y_{33}^{\prime}=$

This implies that:

$$
\begin{aligned}
& {[O]_{3 \times 3}=\left(Y_{11}-\frac{Y_{a b c}}{L}\right) \Delta V_{1}+\frac{Y_{a b c}}{L_{1}} \Delta V_{1}} \\
& -\frac{Y_{a b c}}{L_{1}} \Delta V_{3}-
\end{aligned}
$$

$$
[O]_{3 \times 3}=\left(Y_{22}-\frac{Y_{a b c}}{L}\right) \Delta V_{2}+\frac{Y_{a b c}}{L_{2}} \Delta V_{2}-\frac{Y_{a b c}}{L_{2}} \Delta V_{3}
$$

Variable $\mathrm{L}_{1}$ and $\mathrm{L}_{2} \quad=\quad \mathrm{L} \quad-$

- Since voltages at bus 1 and 2 are continuously measured, therefore $\Delta V_{1}$ and $\Delta V_{2}$ are known equation.

- The unknown equation $(21,22$, and 23) are the fault voltage $\left(\Delta V_{3}\right)$ and fault location are: $\left(\mathrm{L}_{1}\right.$ and $\left.\mathrm{L}_{2}\right)$ respectively.

- However, we can determined and obtained the formulation of fault location $\left(\mathrm{L}_{1}\right)$ as follows:

- Invoking and rewriting equation (21) and (22) into another form we have: 
$-\left(Y_{11}-\frac{Y_{a b c}}{L}\right) \Delta V_{1}=$

$\frac{\Delta V_{1}}{L_{1}} Y_{a b c}-\frac{\Delta V_{3}}{L_{1}} Y_{a b c}=\left(\frac{1}{L_{1}} \Delta V_{1}-\frac{1}{L_{1}} \Delta V_{3}\right) Y_{a b c}$

or

$$
\left(\frac{1}{L_{1}} \Delta V_{1}-\frac{1}{L_{1}} \Delta V_{3}\right) Y_{a b c}=-\left(Y_{11}-\frac{Y_{a b c}}{L}\right) \Delta V_{1}
$$

- Then divide through by $\mathrm{Y}_{\mathrm{abc}}$

$$
=\left(\frac{1}{L_{1}} \Delta V_{1}-\frac{1}{L_{1}} \Delta V_{3}\right) \frac{Y_{a b c}}{Y_{a b c}}=-\left(Y_{11}-\frac{Y_{a b c}}{L}\right) \frac{\Delta V_{1}}{Y_{a b c}}
$$

This implies:

$$
=\left(\frac{1}{L_{1}} \Delta V_{1}-\frac{1}{L_{1}} \Delta V_{3}\right)=-Y_{a b c}{ }^{-1}\left(Y_{11}-\frac{Y_{a b c}}{L}\right) \Delta V_{1}
$$

That is;

$$
\begin{aligned}
& \frac{1}{L_{1}} \Delta V_{1}-\frac{1}{L_{1}} \Delta V_{3}=-Y_{a b c}{ }^{-1}\left(Y_{11}-\frac{Y_{a b c}}{L}\right) \Delta V_{1} \\
=-Z_{a b c} & \left(Y_{11}-\frac{Y_{a b c}}{L}\right) \Delta V_{1} \\
& \frac{1}{L_{1}} \Delta V_{1}-\frac{1}{L_{1}} \Delta V_{3}=Z_{a b c}\left(\frac{Y_{a b c}}{L}-Y_{11}\right) \Delta V_{1}-
\end{aligned}
$$

- $\quad$ Similarly, we can also write as:

$$
\frac{1}{L_{2}} \Delta V_{2}-\frac{1}{L_{2}} \Delta V_{3}=-Y_{a b c}{ }^{-1}\left(Y_{22}-\frac{Y_{a b c}}{L}\right) \Delta V_{2}
$$

Also,

$$
\frac{1}{L_{2}} \Delta V_{2}-\frac{1}{L_{2}} \Delta V_{3}=Z_{a b c}\left(\frac{Y_{a b c}}{L}-Y_{22}\right) \Delta V_{2}
$$

- $\quad$ Further rewriting equation (26) and (27) we have:

$$
\left(\frac{1}{L_{1}}\right) \Delta V_{1}-\left(\frac{1}{L_{1}}\right) \Delta V_{3}=Z_{a b c}\left(\frac{Y_{a b c}}{L}-Y_{11}\right) \Delta V_{1}
$$

- $\quad$ Similarly

$$
\left(\frac{1}{L_{2}}\right) \Delta V_{2}-\left(\frac{1}{L_{2}}\right) \Delta V_{3}=Z_{a b c}\left(\frac{Y_{a b c}}{L}-Y_{22}\right) \Delta V_{2}
$$

This implies that:

$$
X \Delta V_{1}(1)-X \Delta V_{3}(1)=S=Z_{a b c}\left(\frac{Y_{a b c}}{L}-Y_{11}\right) \Delta V_{1}
$$

That is;

$$
=Z_{a b c}\left(\frac{Y_{a b c}}{L}-Y_{11}\right) \Delta V_{1}=S
$$

Similarly;

$$
Y \Delta V_{2}(1)-Y \Delta V_{3}(1)=K=Z_{a b c}\left(\frac{Y_{a b c}}{L}-Y_{22}\right) \Delta V_{2}
$$

That is:

$$
\mathrm{K}=Z_{a b c}\left(\frac{Y_{a b c}}{L}-Y_{22}\right) \Delta V_{2}
$$

To solve for $\mathrm{L}_{1}$, then go back grouping equation (30) and (32) we have

$$
\begin{aligned}
& X \Delta V_{1}(1)-X \Delta V_{3}(1)=S(1) \\
& Y \Delta V_{2}(1)-Y
\end{aligned}
$$

This implies:

- That is, the total length of the transmission line $\mathrm{L}$ is given as:

$\mathrm{L}=\mathrm{L}_{1}+\mathrm{L}_{2}-$ 
But, $X=\frac{1}{L_{1}}, \quad Y=\frac{1}{L_{2}}$

$\Rightarrow \quad L_{1}=\frac{1}{X}, \quad L_{2}=\frac{1}{Y} \quad--$

$\Rightarrow \quad L=\frac{1}{X}+\frac{1}{Y}$

$L=\frac{Y+X}{X y}$

$\Rightarrow \quad L X Y=Y+X$

$$
\begin{array}{llll}
\mathrm{LXY} & -\quad \mathrm{Y} & = & \mathrm{X} \\
Y= & X / L X-1 & - &
\end{array}
$$

- $\quad$ Further expressing equation (34) and (35), we can write;

$$
\begin{aligned}
X \Delta V_{1}(1)-X \Delta V_{3}(1) & =S(1) \\
Y \Delta_{2}(1)-Y \Delta_{3}(1) & =K(1)-
\end{aligned}
$$

- By mathematical manipulation principle their operation;

$\times \Delta V_{1}(1)-S(1)=\times \Delta V_{3}(1)$

$$
Y \Delta V_{2}(1)-K(1)=Y \Delta V_{3}(1)-
$$

From 36: $\quad \frac{X \Delta V_{1}(1)-S(1)}{X}=\Delta V_{3}(1)$

From 37: $\quad \frac{Y \Delta V_{2}(1)-K(1)}{Y}=\Delta V_{3}(1)$

- $\quad$ Since, $X$ and $Y$ can be expressed in term of $\Delta \mathrm{V}_{3}$ then, we can equate them to be equal:

$$
\frac{X \Delta V_{1}(1)-S(1)}{X}=\frac{Y \Delta V_{2}(1)-K(1)}{Y}
$$

- $\quad$ Case 1: for $\frac{1}{X}+\frac{1}{Y}=L$

$$
\begin{array}{ccc}
\frac{Y+X}{X y} & =L \\
X+Y & =L X Y \\
\mathrm{X} & = & \mathrm{Lxy}-\mathrm{y} \\
\mathrm{X} & = & \mathrm{Y}(\mathrm{LX}-1) \\
Y= & X / L X_{-1} &
\end{array}
$$

- $\quad$ Cases 2: For: $\frac{1}{X}+\frac{1}{Y}=\mathrm{L}$

$\frac{Y+X}{X y}=L$

$\mathrm{X}+\mathrm{Y} \quad=\quad$ Lxy

$\mathrm{Y} \quad=\quad \mathrm{Lxy}-\mathrm{X}$

$\mathrm{Y}=\mathrm{X}(\mathrm{Ly}-1)$

$$
X=y / L y^{-1}
$$

- $\quad$ Case 3:

For $\mathrm{L}=\mathrm{L}_{1}+\mathrm{L}_{2}=$ Length of transmission line

- $\quad$ Case 4: Now recalling our previous equation (40):

$$
\frac{X \Delta V_{1}-S(1)}{X}=\frac{Y \Delta V_{2}(1)-K(1)}{Y}
$$

- $\quad$ Substituting values from case 2:

$$
Y=\frac{X}{X L-1} \quad \text { into equation } 40
$$

We have:

That is keeping (LHS) and substituting

$$
Y=\frac{X}{X L-1} \quad \text { in the (RHS), we have: }
$$




$$
\frac{X \Delta V_{1}(1)-S(1)}{X}=\frac{\frac{X}{X L-1} \Delta V_{2}-K(1)}{\frac{X}{X L-1}}
$$

- $\quad$ Now cross - multiplying to the (LHS) and (RHS):

$$
\begin{aligned}
& X\left(\frac{X}{X L-1}\right) \Delta V_{1}(1)-S(1)\left(\frac{X}{X L-1}\right) \\
& =X\left(\frac{X}{X L-1}\right) \Delta V_{2}(1)-K(1) . X-
\end{aligned}
$$

- $\quad$ Bringing the term of voltage for $\left(\Delta \mathrm{V}_{1}\right.$ and $\left.\Delta \mathrm{V}_{2}\right)$ :

$$
\begin{aligned}
& \frac{X}{X L-1} \cdot X \cdot \Delta V_{1}(1)-X \cdot \frac{X}{X L-1} \Delta V_{2}(1) \\
& =\quad \frac{X}{X L-1} \cdot S(1)-X . K(1)
\end{aligned}
$$

- $\quad$ Grouping them together:

$\frac{X}{X L-1} . X\left(\Delta V_{1}(1)-\Delta V_{2}(1)\right)=\frac{X}{X L-1} . S(1)-X . K(1)$

- Dividing through by $\frac{X}{X L-1}$ to both side of the equation:

$$
\frac{\frac{X}{X L-1}}{\frac{X}{X L-1}} . X\left(\Delta V_{1}(1)-\Delta V_{2}(1)\right)=\frac{\frac{X}{X L-1}}{\frac{X}{X L-1}} \cdot S(1)
$$

$$
-\frac{K \cdot X}{\frac{X}{X L-1}}-
$$

Then we can continue as follows:

$$
\begin{aligned}
& \frac{X}{X L-1} \frac{\frac{X^{2} L-1}{X}}{\frac{X}{X}\left(\Delta V_{1}(1)-\Delta V_{2}(1)\right)=} \\
& \frac{X}{X L-1} \cdot S(1)-\frac{X L-1}{X}-. K . X . \frac{X L-1}{X}
\end{aligned}
$$

$$
\begin{array}{ll}
\Rightarrow & \mathrm{X}\left(\Delta \mathrm{V}_{1}(1)-\Delta \mathrm{V}_{2}(1)\right)=\mathrm{S}(1)-\mathrm{K}(\mathrm{XL}-1) \\
\Rightarrow & \mathrm{X}\left(\Delta \mathrm{V}_{1}(1)-\Delta \mathrm{V}_{2}(1)\right)=\mathrm{S}(1)-\mathrm{KXL}+\mathrm{K}(1)
\end{array}
$$

- $\quad$ Expanding the RHS:

$$
\mathrm{X}\left(\Delta \mathrm{V}_{1}(1)-\Delta \mathrm{V}_{2}(1)\right)=\mathrm{S}(1)-\mathrm{X} \operatorname{LK}(1)+\mathrm{K}(1)-
$$

- $\quad$ Collecting like terms of $\mathrm{X}$ and grouping them, we have:

$$
\mathrm{X}\left(\Delta \mathrm{V}_{1}(1)-\Delta \mathrm{V}_{2}(1)\right)+\mathrm{XLK}(1)=\mathrm{S}(1)+\mathrm{K}(1)
$$

This implies that:

$$
\mathrm{X}\left[\Delta \mathrm{V}_{1}(1)-\Delta \mathrm{V}_{2}(1)+\mathrm{LK}(1)\right]=\mathrm{S}(1)+\mathrm{K}(1)
$$

$$
X=\frac{S(1)+K(1)}{\Delta V_{1}(1)-\Delta V_{2}(1) \times L K(1)}
$$

But $X=\frac{1}{L_{1}}, \quad Y=\frac{1}{L_{2}}$ from our relationship, in case, 1, 2, 3 , respectively.

Then; $\mathrm{L}_{1}=1 / X$

$$
\begin{aligned}
\frac{1}{L_{1}} & =\frac{S(1)+K(1)}{\Delta V_{1}(1)-\Delta V_{2}(1)+L K(1)} \\
L_{1} & =\frac{\Delta V_{1}(1)-\Delta V_{2}(1)+L K(1)}{S(1)+K(1)}
\end{aligned}
$$

- $\quad$ Similarly, repeating the same technique for the fault location $\left(\mathrm{L}_{2}\right)$. Since equation $(10-16), \mathrm{L}_{1}$ and $\mathrm{L}_{2}$ are the distances of the fault point - location from Bus 1 and 2 respectively as shown in fig. 2 , above, where $\mathrm{L}$ is the total distance of the long-transmission line.

- $\quad$ Recalling, the equating on case 1 , case 2 , case 3 and case 4 respectively for this considerations.

That is:

Case 1 - $\quad \mathrm{Y}=\quad X / L X-1$

Case 2 -

$$
1 / X+1 / Y=L \quad \text { or } \quad X=Y / L Y-1
$$

Case 3 - $\quad \mathrm{L}=\mathrm{L}_{1}+\mathrm{L}_{2}$ 
Case 4 - $\quad \frac{X \Delta V_{1}(1)-S(1)}{X}=\frac{Y \Delta V_{2}(1)-K(1)}{Y}$

- $\quad$ Similarity, in this case substituting, $\mathrm{X}=\frac{Y}{L Y-1}$

into equation 40:

Now keeping (RHS) and substituting into the (LHS): $\mathrm{X}=$ $\frac{Y}{L Y-1}$

$\frac{X \Delta V_{1}(1)-S(1)}{X}=\frac{Y \Delta V_{2}(1)-K(1)}{Y} \quad$ from equation (40)

$$
\left(\frac{Y}{L Y-1}\right) \frac{\Delta V_{1}(1)-S(1)}{\frac{Y}{L y-1}}=\frac{Y \Delta V_{2}(1)-K(1)}{Y}
$$

- $\quad$ Now cross - multiplying we have;

$$
\begin{aligned}
& Y \cdot\left(\frac{Y}{L Y-1}\right) \cdot \Delta V_{1}(1)-S(1) Y \\
& =\quad Y \cdot\left(\frac{Y}{L Y-1}\right) \cdot \Delta V_{2}(1)-K(1) \cdot\left(\frac{Y}{L Y-1}\right)
\end{aligned}
$$

- Then grouping terms that change in $\mathrm{V}$ that is $(\Delta \mathrm{V})$ together:

$$
\begin{aligned}
& Y\left(\frac{Y}{L Y-1}\right) \cdot \Delta V_{1}(1)-Y\left(\frac{Y}{L Y-1}\right) \Delta V_{2} \\
& S .(1) Y-K(1)\left(\frac{Y}{L Y-1}\right)-
\end{aligned}
$$

- $\quad$ Grouping them and factoring it out:

$Y\left(\frac{Y}{L Y-1}\right) \cdot\left(\Delta V_{1}(1)-\Delta V_{2}(1)\right)=S(1) Y-K(1) \cdot \frac{Y}{L Y-1}$

- $\quad$ Divide through by $\frac{Y}{L Y-1}$ to both side, we have:

$$
\frac{Y \cdot\left(\frac{Y}{L Y-1}\right)}{\left(\frac{Y}{L Y-1}\right)}\left(\Delta V_{1}(1)-\Delta V_{2}(1)\right)=\frac{S(1) Y .}{\left(\frac{Y}{L Y-1}\right)}-K(1)-\frac{\left(\frac{Y}{L Y-1}\right)}{\left(\frac{Y}{L Y-1}\right)}
$$

This means that:

$$
Y \cdot\left(\frac{Y}{L Y-1}\right) \times\left(\frac{L y-1}{Y}\right)\left(\Delta V_{1}(1)-\Delta V_{2}(1)\right)=S(1) Y . \times\left(\frac{L y-1}{Y}\right)-K(1)\left(\frac{Y}{L y-1}\right) \times\left(\frac{L y-1}{Y}\right)
$$

This give us as:

$$
\mathrm{Y}\left(\Delta \mathrm{V}_{1}(1)-\Delta \mathrm{V}_{2}(1)\right)=\mathrm{S}(1)(\mathrm{Ly}-1)-\mathrm{K}(1)-
$$

- Expanding the term and collecting terms of $\mathrm{Y}-$ together.

$$
\mathrm{Y}\left(\Delta \mathrm{V}_{1}(1)-\Delta \mathrm{V}_{2}(1)\right)=\mathrm{LS}(1) \mathrm{Y}-\mathrm{S}(1)-\mathrm{K}(1)-
$$

Then we continue as:

$$
\mathrm{Y}\left(\Delta \mathrm{V}_{1}(1)-\Delta \mathrm{V}_{2}(1)\right)-\mathrm{LS}(1) \mathrm{Y}=-\mathrm{S}(1)-\mathrm{K}(1)-
$$

Simplifying further:

$$
\mathrm{Y}\left[\left(\Delta \mathrm{V}_{1}(1)-\Delta \mathrm{V}_{2}(1)\right)-\mathrm{LS}(1)\right]=-\mathrm{S}(1)-\mathrm{K}(1)-
$$

Simplifying further again:

$$
\mathrm{Y}\left[\left(\Delta \mathrm{V}_{1}(1)-\Delta \mathrm{V}_{2}(1)-\mathrm{LS}(1)\right)\right]=-\mathrm{S}(1)-\mathrm{K}(1)-
$$

Making Y the subject of the expression we have:

$$
Y=\frac{-S(1)-K(1)}{\Delta V_{1}(1)-\Delta V_{2}(1)-L S(1)}
$$

- But from our relationship $\mathrm{X}=\frac{1}{L_{1}}$ and $\mathrm{Y}=\frac{1}{L_{2}}$

$$
\begin{aligned}
& \frac{1}{L_{2}}=\frac{-S(1)-K(1)}{\Delta V_{1}(1)-\Delta V_{2}(1)-L S(1)} \\
& L_{2}=\frac{\Delta V_{1}(1)-\Delta V_{2}(1)-L S(1)}{-S(1)-K(1)}
\end{aligned}
$$


- $\quad$ From our mathematical relationship, the parameters in the equation which defined $\mathrm{S}$ and $\mathrm{K}$ are given as: recalling from previous equation 30 and 33.

- $\quad$ Thus, the fault - location $\mathrm{L}_{1}$ and $\mathrm{L}_{2}$ are developed and modeled as:

$$
\begin{aligned}
& \mathrm{S}=\mathrm{X} \Delta \mathrm{V}_{1}(1)-\mathrm{X} \Delta \mathrm{V}_{3}(1)- \\
& =\quad Z a b c\left(\frac{Y a b c}{L}-Y_{11}\right) \Delta V_{1}
\end{aligned}
$$

And

$$
L_{1}=\frac{\Delta V_{1}(1)-\Delta V_{2}(1)+L K(1)}{S(1)+K(1)}
$$

and

$$
L_{2}=\frac{\Delta V_{1}(1)-\Delta V_{2}(1)-L S(1)}{-S(1)-K(1)}
$$

$$
\begin{aligned}
\mathrm{K}=\mathrm{Y} \Delta \mathrm{V}_{2}(1)-\mathrm{Y} \Delta \mathrm{V}_{3}(1) & \\
= & Z a b c\left(\frac{Y a b c}{L}-Y_{22}\right) \Delta V_{2}
\end{aligned}
$$

Fig 1:

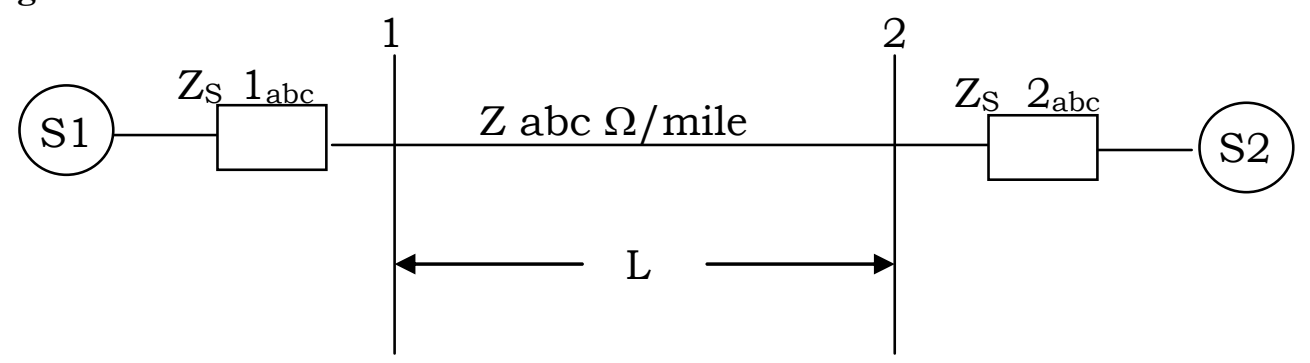

Fig 1: Long transmission line considered for this analysis (long - line $=200$ mile $=320 \mathrm{~km}$ ).

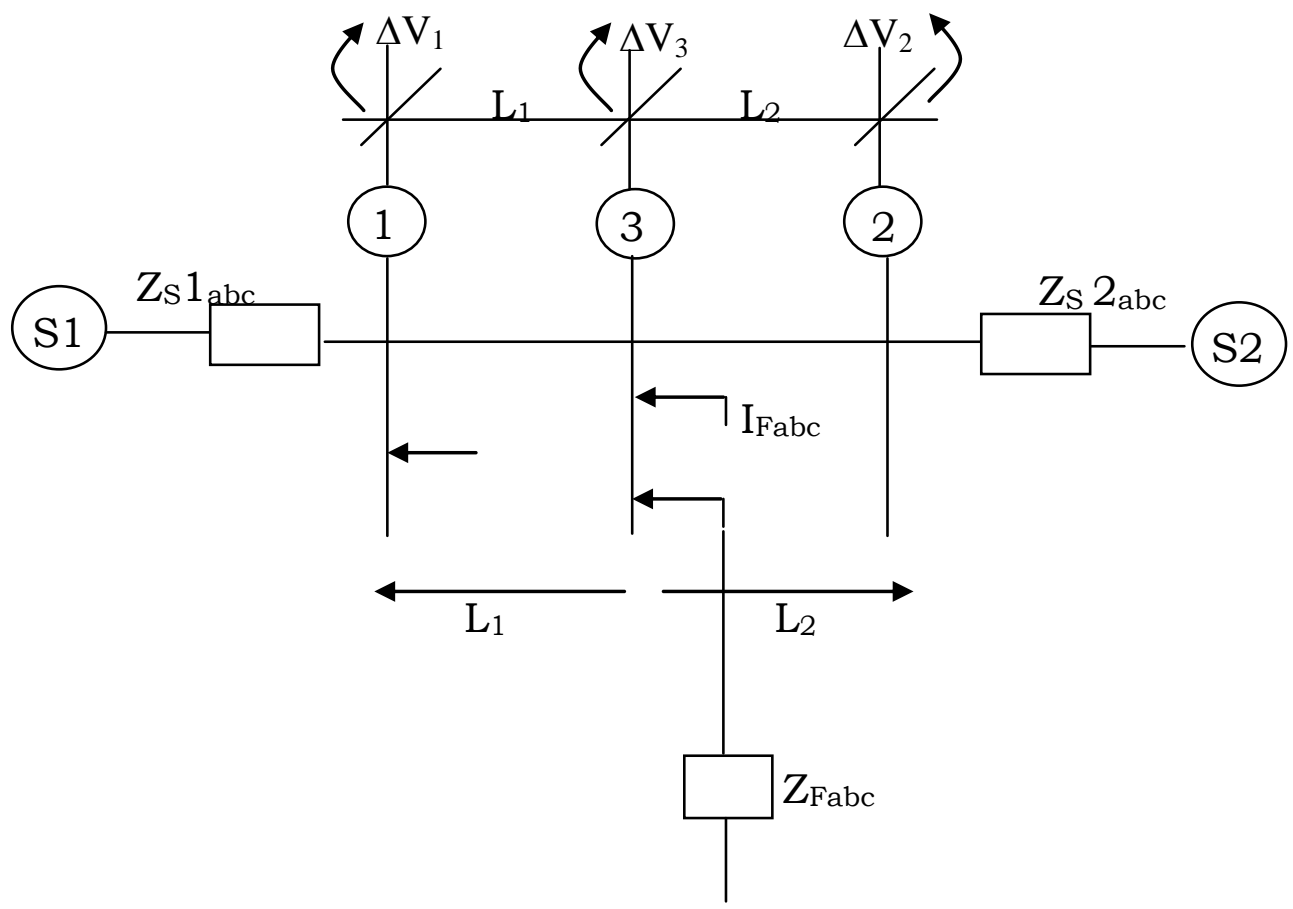

Fig. 2: Transmission line with a fault (bus 3 introduced due to fault initiation).

- $\quad$ Parameter data for the line are:

$\mathrm{R}_{1} \quad=\quad 0.249168 \Omega / \mathrm{mile}$ 


$\begin{array}{lll}\mathrm{L}_{1} & = & 0.00156277 \mathrm{H} / \mathrm{mile} \\ \mathrm{C}_{1} & = & 19.469 \mathrm{E}-9 \mathrm{~F} / \mathrm{mile} \\ \mathrm{R}_{\mathrm{o}} & = & 0.60241 \Omega / \mathrm{mile} \\ \mathrm{L}_{\mathrm{o}} & = & 0.0048303 \mathrm{H} / \mathrm{mile} \\ \mathrm{C}_{\mathrm{o}} & = & 12.06678 \mathrm{E}-9 \mathrm{~F} / \mathrm{mile}\end{array}$

- The source impedance are as follows:

Sending End:

$$
\begin{aligned}
\mathrm{Zs}_{1}= & 17.177+\mathrm{j} 45.5285 \Omega \\
\mathrm{Z}_{\mathrm{so}}= & 2.5904+\mathrm{j} 14.7328 \Omega \\
- & \text { Receiving End: } \\
\mathrm{Z}_{\mathrm{s} 1}= & 15.31+\mathrm{j} 45.9245 \Omega \\
\mathrm{Z}_{\mathrm{so}}= & 0.7229+\mathrm{j} 25.1288 \Omega
\end{aligned}
$$

\section{RECOMMENDATIONS}

- However, it is requested and recommended that because of fault inevitability and contingency of occurrence of fault introduced into transmission line which in other words could drastically cause a large voltage - drop and could not be tolerated in practice.

- In practice, line are therefore required to incorporate series capacitors to reduce series reactance and the load - current power factor which would increase from 0.9 lag to near unity by the use of shunt capacitors or synchronous compensators at the receiving end.

- The characteristic impedances $Z_{0}$ is also know as the surge impedance, when a line is terminated in its characteristic impedance, the power delivered is know as the natural load.

- $\quad$ For a loss-free line under natural load conditions the reactive power absorbed by the line is equal to the reactive power generated, this mean that:

$$
\frac{V^{2}}{X_{c}}=I^{2} X L
$$

And

$$
\frac{V}{I}=Z_{o}=\sqrt{(X L X C)}=\sqrt{\frac{L}{C}}
$$

- $\quad$ At this load V and I are in phase all along the line and optimum transmission conditions obtained.

- $\quad$ However in Practice the load impedances are seldom in the order of $Z_{0}$. values of $Z_{0}$ for various line voltages are as follows, values of the corresponding natural loads are shown in breakers: $132 \mathrm{KV}, 152 \Omega(50 \mathrm{mw})$;

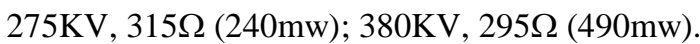

- The angle of the impedances varies between $\mathrm{O}$ and $15^{0}$. For underground cable $Z_{\mathrm{o}}$ (characteristic impedance $=$ surge impedance or is about one tenth of the overhead line value.

- $\quad$ Parameter of transmission line:

$$
\begin{array}{ll}
\mathrm{R} & =\text { Resisters/unit length } \\
\mathrm{L} & \text { = Inductance/unit length } \\
\mathrm{G} & \text { = Leakage/unit length } \\
\mathrm{C} & \text { = Capacitance/unit length } \\
\mathrm{Z} & =\text { Impedance/unit length } \\
\mathrm{Y} & =\text { Shunt admittance/unit length } \\
\mathrm{Z} & =\text { Total series impedance of the line } \\
\mathrm{Y} & \text { = Total shunt admittance of the line }
\end{array}
$$

- $\quad$ Since $\mathrm{Z}_{\mathrm{o}}$ is the input impedance of an infinite length of the line, if any line is terminated in $Z_{0}$ its input impedance is also $\mathrm{Z}_{\mathrm{o}}$.

- $\quad$ The propagation constant $(\mathrm{P})$ represents the changes occurring in the transmitted waves, as its progresses along the line, $\alpha$ measures the attenuation, and $\beta$ measure angular phase shift. i.e.

$$
P=(\alpha+j \beta)
$$

- $\quad$ Similarly for a loss free-line, $\mathrm{P}=\mathrm{jw} \sqrt{(L C)}$ and $\beta=$ $\mathrm{w} \sqrt{(L C)}$ with a velocity of propagation $3 \mathrm{x}$ $10^{5} \mathrm{~km} / \mathrm{sec}$, the wave length of the transmitted voltage and currents at $50^{\mathrm{c}} \mathrm{s}$ is $6000 \mathrm{~km}$.

- Thus lines are much shorter than the wave length of the transmitted energy.

\section{REFERENCES}

[1] R.O. Berglund, W.A Mttelatadt, M.L. Shelton, P. Barkan, C.G. Dewey and K.M. Skreiner, "One-cycle fault interruption at $500 \mathrm{KV}$ : system benefits and breaker design", IEEE Transactions on power Aparatus and systems, vol. PAS-93, No. 5, Pp. 1248, September/October 1974.

[2] R.J. Cornick, Y.M. Ko and B. Pek, "Power System Transients caused by arcing faults", IEE proceedings, vol. 128, Pt. C, No. 1. January 1981, pp. 18-27.

[3] J.P Bickford, M.H. Abdel-Rahuman, "Application of traveling wave methods to the calculation of transientfault current and voltages in Power system networks," IEE Proceedings, vol. 127 Pt.C, 3, May 1980, Pp. 153168.

[4] B. Pek "Power System Transients caused by arching faults", Ph.D Thesis, UMIST, Victoria University of Manchester, Manchester, U.K., 1977

[5] A.A. Girgis and R. Grover Brown, "Application of Transactions on Power Apparatus and System", vol. PAC-100, No. 7, pp. 3387-3397, July 1981.

[6] N. Ghana and S. Lieberman, "Vltra high speed relay for ZRV/UHV Transmission lines-Development design and application, IEEE Transactions on Power Application and systems, vol. Pas-97 No. 6 up 21042116, November/December 1978. 